\title{
Prevalence and determinant factors of intestinal parasites among school children in Arba Minch town, Southern Ethiopia
}

\author{
Desta Haftu $^{1}$, Negussie Deyessa ${ }^{2}$, Eskzyiaw Agedew ${ }^{1}$ \\ ${ }^{1}$ Department of Public Health, College of Medicine and Health Sciences, Arbaminch University, Arbaminch, Ethiopia \\ ${ }^{2}$ Department of Preventive Medicine, School of Public Health, Addis Ababa University, Addis Ababa, Ethiopia \\ Email address: \\ destish.haf@gmail.com(D. Haftu),negdaysun@yahoo.com (N. Deyessa), esk1agid@gmail.com(E.Agedew)
}

\section{To cite this article:}

Desta Haftu, Negussie Deyessa, Eskzyiaw Agedew. Prevalence and Determinant Factors of Intestinal Parasites among School Children in Arba Minch Town, Southern Ethiopia. American Journal of Health Research. Vol. 2, No. 5, 2014, pp. 247-254.

doi: 10.11648/j.ajhr.20140205.15

\begin{abstract}
Back ground: Intestinal parasitic infections are still quite common in developing countries including Ethiopia, particularly in children. They are mostly associated with unsafe and low quality of drinking water, poor personal and environmental sanitation. Thus, the objective of this study was to assess the prevalence and determinant factors of intestinal parasites among school children. Methods: A cross sectional study was conducted in March, 2014, among 498 students selected from three governmental elementary schools in Arbaminch- town, Southern Ethiopia using stratified multistage sampling method. Structured questionnaire was used to identify environmental, socio demographic and behavioral factors. Stool specimens were collected from all study subjects and were examined for intestinal parasites using direct smear (mount examination) and Formal-ether concentration techniques. Finally, data entry and analysis was done using Epi-info and SPSS statistical soft ware respectively. A bivariate and multivariate logistic regression analysis was done. P value less than 0.05 was considered as statistically significant. Results: A total of nine parasites were detected .The overall prevalence of intestinal parasites was $27.7 \%$ (95\% confidence interval (CI): (23.8-31.6\%)). The predominant parasite was E.histolytica/dispar 64(12.9\%) followed by A.lumboricoids 53(10.6\%), H.nana 21 (4.2\%) and G.lamblia 21 (4.2\%). Hand washing practice before meal $[\mathrm{AOR}=5.7 ; 95 \% \mathrm{CI}(3.4,9.7)]$, nail hygiene $[\mathrm{AOR}=2.6 ; 95 \% \mathrm{CI}(1.5,4.4)]$, and children's mother educational level [ A OR $=3.5 ; 95 \%$ CI $(1.01,11.4)$ ] showed statistically significant association with high rates of intestinal parasitic infections. Conclusion and recommendations: The prevalence of intestinal parasites is high in the study area among school children. Thus, it indicates the need of interventions like health education regarding to personal hygiene and mass treatment.
\end{abstract}

Keywords: Intestinal Parasites, School Children, Prevalence, Determinant Factors, Ethiopia

\section{Introduction}

Intestinal parasitic infections (IPIs) are distributed virtually throughout the world. According to the World Health Organization (WHO) estimates, globally about 3.5 billion people are affected by intestinal parasitic infections and cause clinical morbidity in approximately 450 million, majorities of the cases occur among children (1).

Intestinal parasitic infections such as Ascariasis, hookworm infection and Trichiuriasis are among the ten most common infections in the world and each constituting of 1000 million, 900 million, and 500 million respectively, being responsible for considerable morbidity and mortality.
Beside of causing morbidity and mortality, infections with intestinal parasites have been associated with stunting, physical weakness and low educational performance of schoolchildren. These infections are more prevalent among the poor segments of the population and intimately linked with low economic level, poor personal and environmental sanitation, and overcrowding, limited access to clean water, tropical climate and low altitude (1-3).

The degree of harm caused by intestinal parasitic infections to the health of individuals and communities depends on: the parasite species, the intensity and course of infection, the nature of interactions between the parasite species and concurrent infection, the nutritional and 
immunological status, and numerous socioeconomic factors of the populations. Thus, it is generally extremely difficult to measure the suffering caused by intestinal parasitic infections because so many cases of the diseases are asymptomatic and therefore remain undetected(1).

Another study which was done in children of aged 17 years and below from East African countries showed 50\% prevalence rate and all infected children were asymptomatic at diagnosis (4).

Intestinal helminths are more prevalent through out the tropics, especially among poor communities that is often neglected. In these parts of the world the high prevalence rate of intestinal parasites is attributed largely to socioeconomic status, poor sanitation, inadequate medical care and absence of safe drinking water supplies. Records show increasing trends in helminthiasis infections, particularly in developing nations(3).

Regarding to intestinal protozoan infections, Giardiasis caused by Giardia duodenalis, is the most predominant protozoa infection with an estimated prevalence rates ranging from 2.0 to $7.0 \%$ in developed countries and 20.0 to $30.0 \%$ in most developing countries, affecting approximately 200 million people worldwide (5). Amoebiasis due to infections with the intestinal protozoon Entamoeba histolytica results in 40,000-100,000 deaths each year (6). The opportunistic protozoa, Cryptosporidium $s p$. has also emerged as an important cause of diarrheal illnesses worldwide particularly in young children and immuno-compromised patients with a prevalence of $4 \%$ in developed countries and three to four times more frequent in developing countries(7).

School children carry the heaviest burden of the associated morbidity (8), due to their dirty habits of playing or handling of infested soils, eating with soiled hands, unhygienic toilet practices, drinking and eating of contaminated water and food $(9,10)$.

In Ethiopia, like in other developing countries, intestinal parasitic infections are widely spread. Several studies indicated that the prevalence of helminthic infections were high in the lower altitudes (11) and A. lumbricoides the most prevalent intestinal parasites in different communities usually occurring together with Trichuris and hook worm $(12,13)$. Ethiopia has one of the lowest quality of drinking water supply and latrine coverage in the world $(11,14)$. The distribution and prevalence of various species of intestinal parasites differs from region to region because of several environmental, social and geographical and other factors mentioned above. Hence, study on the prevalence of various intestinal parasitic infections is a prerequisite not only for formulation of appropriate control strategies but also to predict risk for communities under consideration. Thus, the objective of this study was to assess the current epidemiological prevalence of intestinal parasites and the associated risk factors favouring the spread of parasites.

\section{Methods and Materials}

\subsection{Study Area, Design and Period}

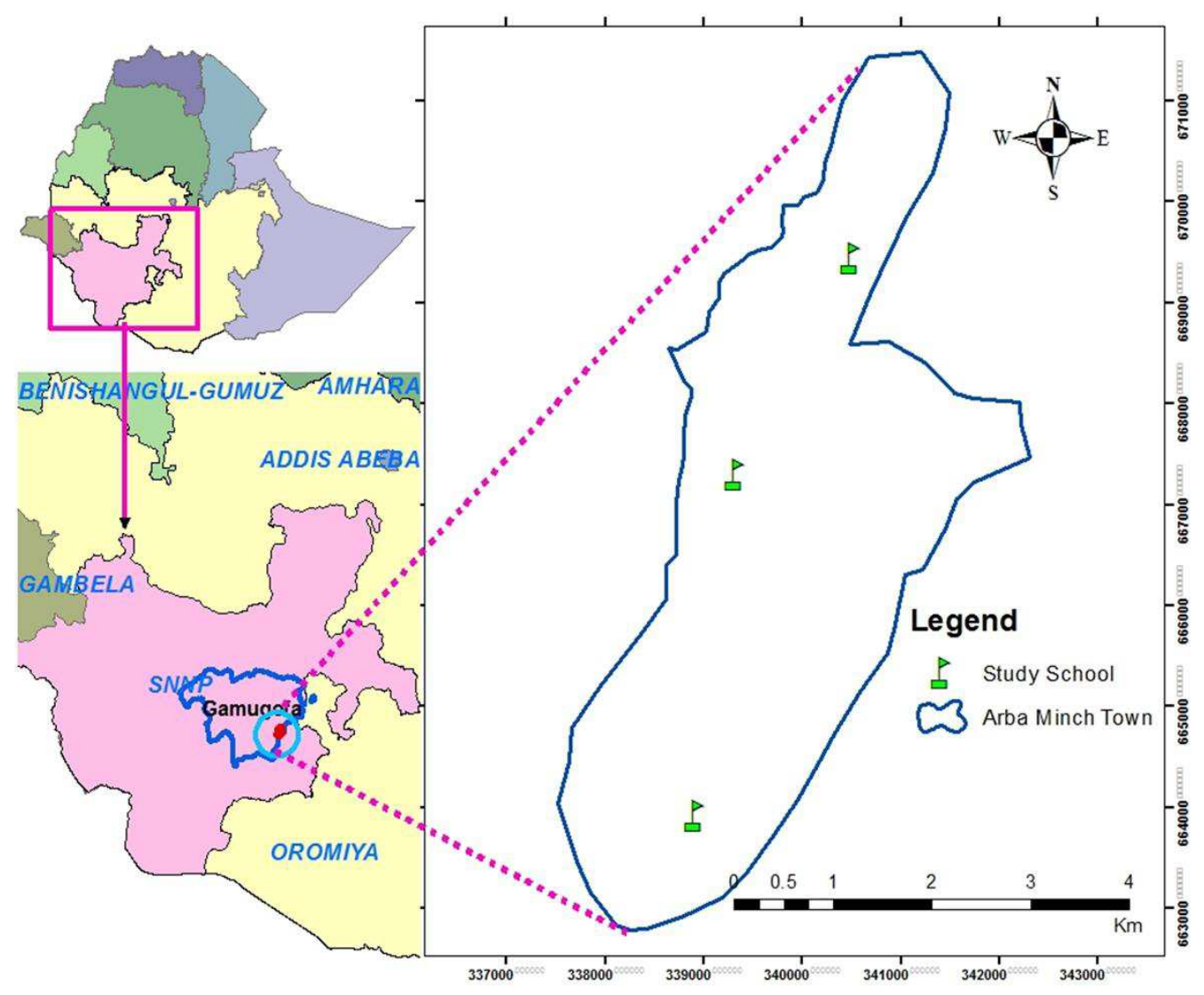

Figure 1. Map of study area 
A cross sectional study design was conducted in March 2014, in Arbaminch town which is capital city of Gamo Gofa zone, (Southern Nation, Nationality and Peoples Region, (SNNPR)) and Arbaminch Zuria wereda. Arbaminch is located at about $505 \mathrm{kms}$ South of Addis Ababa, at an elevation of 1285 meters above sea level and has a total area of 12, 581.4 square kms. Besides the forty springs crossing the town is a river "Kulfo ", which is used by the local people for washing cloths and farming which predisposes the children to water-borne diseases during swimming, washing, playing, and crossing the water. Based on the 2007 Census conducted by the CSA, this town has a total population of 74,879 . There are six elementary schools in the town with a total number of 12,461 students attending during the study period. Of whom, 6389 are female and 6072 are males.

\subsection{Study Population, Sample Size Determination and Sampling Technique}

The sample size (n) was estimated using the single population proportion formula Z2 p (1-p) / d2. Where $\mathrm{P}=$ proportion of intestinal parasites from previous study, $\mathrm{d}=$ margin of error and $\mathrm{Z}=$ standard score corresponds to1.96. design effect of 1.5 was used. The proportion (p) of intestinal parasites from previous study was $71 \%$ (15). For the calculation, a $95 \%$ confidence interval and a $5 \%$ margin of error were used. To minimize errors arising from the likelihood of non-compliance, five percent of the sample size was added giving a final sample size of 498.

Three government elementary schools were selected from six schools found in the town by simple random sampling methods. To select the study subjects, the students were first stratified according to their educational level (Grade 1 to Grade 8) for each school and allocation of student was done proportional to the number of students in each school and grade level. Finally, the study subjects were selected using systematic random sampling by using class roster as the sampling frame.

\subsection{Data Collection and Parasitological Investigation}

A pre-tested structured questionnaire was developed and modified based on possible determinant factors that was applied in different similar studies related to this study in English and then was translated into the local language(Amharic ) and back translated to English .One supervisor and three data collectors were selected and trained for this purpose At the end of the day all the questionnaires were checked for consistency and completeness.

After proper instruction, each student was provided with labeled/ with unique identification numbers (IDs), clean, dry, and leak proof stool cup and pieces of applicator sticks to bring proper fresh stool. Every child was instructed to bring his own sufficient amount of stool so that no mixing up occurs. On delivery of the stool specimen, each child was interviewed using a structured questionnaire for demographic and determinant factors for intestinal parasites. Stool samples were examined for intestinal parasites using direct smear (mount examination) and Formal-ether concentration techniques. A portion of each stool samples was processed with a direct microscopic technique to detect cysts, trophozoites, eggs and larva of intestinal parasites immediately at the school. The remaining part of the samples was preserved in $10 \%$ formalin solution and transported to Arba Minch University College of Medicine and Health science and processed using formal- ether concentration technique. It was processed by two senior laboratory technologists who were trained for this purpose.

\section{Data Management and Analysis}

Data was entered and cleaned using Epi info version 3.5.3 and analyzed by SPSS (Statistical Package for Social Sciences) version 21.0 soft ware. Descriptive statistics were done to assess the prevalence and distribution of intestinal parasites.

Logistic regression analysis was performed to determine the independent effect of the independent variables with dependent variable by calculating the strength of the association between intestinal parasites infection and determinant factors using odds ratio (OR) and 95\% confidence interval (CI). Crude OR and adjusted OR were estimated by bivariate and multivariate logistic regression analysis with respective $95 \%$ CIs respectively. $\mathrm{P}$ value less than 0.05 was considered as statistically significant.

\subsection{Data Quality Assurance}

To ensure reliable information:-Before the data collection period, the questionnaire and laboratory materials was pretested in the randomly selected students on $5 \%$ of the total sample size. Training for data collectors was done. Standard operating procedures were used for specimen collection and processing for maintaining a good quality study. The use of two different techniques, direct smear and Formal-Ether concentration for diagnosis of the parasite were also used as a quality control. Ten percent of the slides was randomly selected and re-examined at the end by experienced laboratory technologist who was blind for the first examination result to ensure quality control. The result of laboratory examination was recorded on well prepared format carefully and finally it was attached with the questionnaire.

\subsection{Ethical Consideration}

Prior to the commencement of the study approval letter was obtained from Ethiopian Institute of Water Resource, Addis Ababa University. Permission was also obtained from Arbaminch education, and health offices, authority of the schools to conduct the study. Informed verbal consent was obtained from students and school directors. The 
students' privacy during the interview and stool collection was maintained and the data obtained from them were strictly kept confidential. Finally, the study participants who were found positive for intestinal parasites were treated with the standard regimen for free by local health professionals

\section{Results}

\subsection{Socio Demographic Characteristics}

All of the study participants, 498 school children were participated and included in the analysis, providing $100 \%$ response rate. There were $243(48.8 \%)$ males and $255(51.2 \%)$ females. The mean $( \pm \mathrm{SD})$ age of the children was $10.72( \pm 2.55)$ years. Of the total 498 students, $311(62.4 \%)$ were in the age group of 10-14 years (Table1).

Table 1. Frequency of distribution among school children by sociodemographic characteristics, Arbaminch town, Southern Ethiopia, March, 2014.

\begin{tabular}{|c|c|c|}
\hline Socio demographic characteristics & Frequency & Percent \\
\hline \multicolumn{3}{|l|}{ Sex } \\
\hline Male & 243 & 48.8 \\
\hline Female & 255 & 51.2 \\
\hline \multicolumn{3}{|l|}{ Residence } \\
\hline Urban & 462 & 98.8 \\
\hline Rural & 36 & 7.2 \\
\hline \multicolumn{3}{|l|}{ Grade level } \\
\hline Grade1 & 75 & 15.1 \\
\hline Grade 2 & 60 & 12 \\
\hline Grade 3 & 51 & 10.2 \\
\hline Grade 4 & 61 & 12.2 \\
\hline Grade 5 & 47 & 9.4 \\
\hline Grade 6 & 41 & 8.2 \\
\hline Grade 7 & 65 & 13.1 \\
\hline Grade 8 & 98 & 19.7 \\
\hline \multicolumn{3}{|l|}{ Religion } \\
\hline Orthodox & 275 & 55.2 \\
\hline Protestant & 217 & 43.6 \\
\hline Muslim & 6 & 1.2 \\
\hline \multicolumn{3}{|l|}{ Ethnicity } \\
\hline Gamo & 442 & 88.8 \\
\hline Wolayta & 22 & 4.4 \\
\hline Amhara & 14 & 2.8 \\
\hline Oromo & 7 & 1.4 \\
\hline Others & 13 & 2.6 \\
\hline \multicolumn{3}{|l|}{ Age category of respondents in years } \\
\hline$\leq 9$ & 152 & 30.5 \\
\hline $10-14$ & 311 & 62.4 \\
\hline $15+$ & 35 & 7 \\
\hline \multicolumn{3}{|l|}{ Fathers educational status } \\
\hline Unable to write and read & 91 & 18.3 \\
\hline Able to write and read & 37 & 7.4 \\
\hline Grade $1-4$ & 50 & 10 \\
\hline Grade $5-8$ & 117 & 23.5 \\
\hline Grade $9-12$ & 133 & 26.7 \\
\hline Above diploma & 70 & 14.1 \\
\hline \multicolumn{3}{|l|}{ Mothers educational status } \\
\hline Unable to write and read & 112 & 22.5 \\
\hline Able to write and read only & 39 & 7.8 \\
\hline Grade $1-4$ & 64 & 12.9 \\
\hline
\end{tabular}

\begin{tabular}{lll}
\hline Socio demographic characteristics & Frequency & Percent \\
\hline Grade 5-8 & 151 & 30.3 \\
Grade 9-12 & 94 & 18.9 \\
Diploma and above & 38 & 7.6 \\
Fathers educational status & & \\
Unable to write and read & 91 & 18.3 \\
Able to write and read & 37 & 7.4 \\
Grade 1-4 & 50 & 10 \\
Grade 5-8 & 117 & 23.5 \\
Grade 9-12 & 133 & 26.7 \\
Above diploma & 70 & 14.1 \\
Mothers educational status & & \\
Unable to write and read & 112 & 22.5 \\
Able to write and read only & 39 & 7.8 \\
Grade 1-4 & 64 & 12.9 \\
Grade 5-8 & 151 & 30.3 \\
Grade 9-12 & 94 & 18.9 \\
Diploma and above & 38 & 7.6 \\
\hline
\end{tabular}

\subsection{Prevalence of Intestinal Parasites}

Nine species of intestinal parasites were identified with an overall prevalence $(95 \% \mathrm{CI})$ of $27.7 \%(23.8 \%, 31.6 \%)$. The predominant parasite was E.histolytica/dispar which was observed in 64(12.9\%) students followed by A.lumboricoids 53(10.6\%) students, H.nana and G.lamblia $21(4.2 \%)$ each (Table2).

Among the 138 positive individuals, the majority, 108 $(21.7 \%)$ had single infection and 35(7\%) individuals had multiple infection or poly parasitism. Of these multiple infections, twenty five (5\%), and 5(1.00\%) harboured dual, triple and above infections concurrently respectively.

Table 2. Number of males and females positive for at least one of intestinal parasites (s) among Arbaminch town school children, Southern Ethiopia, March 2014

\begin{tabular}{lllllll}
\hline \multirow{2}{*}{ Intestinal parasites } & \multicolumn{2}{l}{ Male } & \multicolumn{3}{c}{ Female } & \multicolumn{1}{c}{ Total } \\
\cline { 2 - 7 } & $\mathbf{N 0}$ & $\mathbf{\%}$ & $\mathbf{N o}$ & $\mathbf{\%}$ & No & $\%$ \\
\hline Protozoans & & & & & & \\
E.histolytica/dispar & 34 & 14 & 30 & 11.8 & 64 & 12.9 \\
G.lamblia & 12 & 4.9 & 9 & 3.5 & 21 & 4.2 \\
Helminthes & & & & & & \\
A.lumboricoids & 27 & 11.1 & 26 & 10.2 & 53 & 10.6 \\
T.trichuria & 3 & 1.2 & 4 & 1.6 & 7 & 1.4 \\
S.stercolaris & 3 & 1.2 & 0 & 0 & 3 & 0.6 \\
H.worm & 3 & 1.2 & 8 & 3.1 & 11 & 2.2 \\
H.nana & 11 & 4.5 & 10 & 3.9 & 21 & 4.2 \\
Taenia spp. & 1 & 0.4 & 5 & 2 & 6 & 1.2 \\
E.vermicularis & 1 & 0.4 & 3 & 1.2 & 4 & 0.8 \\
Over all & 67 & 27.6 & 71 & 27.8 & 138 & 27.7 \\
\hline
\end{tabular}

NB: The sum of the columns is greater than the total because of the co infections of some of the students.

\subsection{Determinant Factors for Intestinal Parasitic Infections}

Among the potential determinant factors analyzed using bi-variate logistic regression most common behavioural and environmental risk factors that have previously been described to have an impact on parasitism were not 
associated with parasite infections in this study population except, children mothers' educational level, regular practice of hand washing before feeding of the study participant, and fingers nail status of the children that were significantly associated with any of the identified intestinal parasite(s) as shown in table 3 and 4.

There was no significant difference of the IPIs between male and female although female $(51.4 \%$ had slightly higher overall prevalence rate compared to male (48.6\%). Similarly, although there was no statistically significant association between age and parasitic infection, the highest parasite prevalence was reported among the age group of 10-14 years $(\mathrm{P}>0.05)$.
Adjustment of the confounding variables was done using multivariate logistic regression analysis model. Accordingly, the children of illiterate women were more likely to get infection for at least one intestinal parasite than those who had higher educational level $[\mathrm{AOR}=3.5 ; 95 \%$ CI(1.07,11.4)], children who did not wash their hands before eating [AOR 5.7; 95\% CI $(3.4,9.7)$ ] were more likely to acquire intestinal parasites infection than children who wash their hands before meal regularly. Similarly, children who had dirty materials in their fingers $[\mathrm{AOR}=2.6$; $95 \%$ CI $(1.5,4.4)]$ were two times more likely to acquire intestinal parasitic infections than their counter parts who had no dirty materials in their fingers (Table 3 and 4).

Table 3. Intestinal parasites by socio demographic characteristics among students of Arbaminch Elementary Schools in Arbaminch, Southern Ethiopia, March, 2014.

\begin{tabular}{|c|c|c|c|c|c|}
\hline \multirow{2}{*}{ Socio demographic characteristics } & \multicolumn{2}{|c|}{ Intestinal parasites } & \multirow{2}{*}{ P-value } & \multirow{2}{*}{$\operatorname{COR}(95 \% C I)$} & \multirow{2}{*}{$\operatorname{AOR}(95 \% C I)$} \\
\hline & Positive & Negative & & & \\
\hline \multicolumn{6}{|l|}{ Sex } \\
\hline Male & $67(27.6)^{*}$ & $176(72.4)$ & \multirow[t]{2}{*}{0.95} & $0.99(0.67,1.46)$ & $1.07(.73,2)$ \\
\hline Female & $71(27.8)$ & $184(72.2)$ & & 1.00 & 1.00 \\
\hline \multicolumn{6}{|l|}{ Grade level } \\
\hline Grade1 & $22(29.3)$ & $53(70.7)$ & \multirow{8}{*}{0.56} & $0.9(0.46,1.73$ & $1.36(.35,5.3)$ \\
\hline Grade 2 & $15(25)$ & $45(75)$ & & $0.72(0.35,1.49)$ & $0.58(0.18,1.9)$ \\
\hline Grade 3 & $15(29.4)$ & $36(70.6)$ & & $0.9(0.43,1.9)$ & $0.8(0.3,2.4)$ \\
\hline Grade 4 & $11(18)$ & $50(82)$ & & $0.475(0.2,1.04)$ & $0.27(0.1,0.7)$ \\
\hline Grade 5 & $10(21.3)$ & $37(78.7)$ & & $0.58(00.26,1.3)$ & $0.57(0.2,1.5)$ \\
\hline Grade 6 & $13(31.7)$ & $28(68.3)$ & & $1.00(0.46,2.2)$ & $0.96(0.37,2.5)$ \\
\hline Grade 7 & $21(32.3)$ & $65(100)$ & & $1 . .03(0.53,2.02)$ & $0.9(0.38,2.2)$ \\
\hline Grade 8 & $31(31.6)$ & $67(68.4)$ & & 1.00 & 1.00 \\
\hline \multicolumn{6}{|l|}{ Religion } \\
\hline Orthodox & $71(25.8)$ & $204(74.2)$ & 0.62 & $1.7(0.2,15.15)$ & $2.5(0.2,27.6)$ \\
\hline Protestant & $66(30.4)$ & $151(69.6)$ & \multirow[t]{2}{*}{0.48} & $2.2(0.25,19.07)$ & $2.3(0.2,25.7)$ \\
\hline Muslim & $1(16.7)$ & $5(83.3)$ & & 1.00 & 1.00 \\
\hline \multicolumn{6}{|l|}{ Ethnicity } \\
\hline Gamo & $123(27.8)$ & $319(72.2)$ & \multirow{5}{*}{0.5} & $0.62(0.2,192)$ & $0.7(0.2,3)$ \\
\hline Wolayta & $7(31.8)$ & $15(68.2)$ & & $0.75(0.18,3.13)$ & $0.7(0.12,4.3)$ \\
\hline Amhara & $1(7.1)$ & 13(92.9) & & $0.12(0.01,1.25)$ & $0.24(0.02,3.14)$ \\
\hline Oromo & $2(28.6)$ & $5(71.4)$ & & $0.64(0.09,4.66)$ & $0.2(0.02,2.6)$ \\
\hline Others & $5(38.5)$ & $8(61.5)$ & & 1.00 & \\
\hline \multicolumn{6}{|l|}{ Age category of respondents in years } \\
\hline$\leq 9$ & $40(26.3)$ & $112(73.7)$ & .673 & $1.21(.51,2.87)$ & $1.08(0.3,4.7)$ \\
\hline $10-14$ & $90(28.9)$ & $221(71.1)$ & .451 & $1.37(.6,3.14)$ & $2.3(0.78,6.5)$ \\
\hline $15+$ & $8(22.9)$ & $27(77.1)$ & & 1.00 & 1.00 \\
\hline \multicolumn{6}{|l|}{ Fathers educational status } \\
\hline Unable to write and read & $22(24.2)$ & $10(27)$ & \multirow{6}{*}{0.09} & $1.4(0.65,3.02)$ & $0.6(0.2,1.7)$ \\
\hline Able to write and read only & $69(75.8)$ & $27(73)$ & & $1.62(0.63,4.17)$ & $1.2(0.34,4.3)$ \\
\hline Grade $1-4$ & $18(36)$ & $32(64)$ & & $2.47(1.07,5.68)$ & $2.13(0.68,6.6)$ \\
\hline Grade 5-8 & $42(35.9)$ & $75(64.1)$ & & $2.46(1.21,5.00)$ & $2.8(1.07,7.45)$ \\
\hline Grade 9-12 & $33(24.8)$ & $100(75.2)$ & & $1.45(0.71,2.97)$ & $1.37(0.5,3.5)$ \\
\hline Above diploma & $13(18.6)$ & $57(81.4$ & & 1.00 & 1.00 \\
\hline \multicolumn{6}{|l|}{ Mothers educational status } \\
\hline Unable to write and read & $61(42.7)$ & $82(57.3)$ & \multirow{6}{*}{$<0.001$} & $2.98(1.22,7.26)$ & $3.5(1.07,11.4)$ \\
\hline Able to write and read only & $15(35.7)$ & $27(64.3)$ & & $2.22(0.78,6.3)$ & $3.3(0.86,12.3)$ \\
\hline Grade $1-4$ & $11(18.6)$ & $48(81.4)$ & & $0.92(0.32,2.64)$ & $0.68(0.2,2.5)$ \\
\hline Grade $5-8$ & $23(17.4)$ & $109(82.6)$ & & $0.84(0.33,2.17)$ & $0.78(0.2,2.6)$ \\
\hline Grade 9-12 & $21(24.1)$ & $66(75.9)$ & & $1.27(0.49,3.33)$ & $1.8(0.54,5.9)$ \\
\hline Diploma and above & $7(20)$ & $28(80)$ & & 1.00 & 1.00 \\
\hline
\end{tabular}

* Figures in parenthesis indicate percentages; $\mathrm{COR}=$ Crude Odd Ratio, $\mathrm{CI}=$ Confidence Interval, $\mathrm{AOR}=$ Adjusted Odd Ratio 
Table 4. Association of environmental and behavioral determinant factors with intestinal parasitic infections among school children in Arbaminch town, Southern Ethiopia, March, 2014.

\begin{tabular}{|c|c|c|c|c|c|}
\hline Determinant factors & $\begin{array}{l}\text { Positive } \\
\mathrm{n}=138\end{array}$ & $\begin{array}{l}\text { Negative } \\
\mathbf{n}=\mathbf{3 6 0}\end{array}$ & $P$-value & $\operatorname{COR}(95 \% \mathrm{CI})$ & $\operatorname{AOR}(95 \% C I)$ \\
\hline \multicolumn{6}{|c|}{ Source of water for drinking } \\
\hline Tap water & $129(26.9)^{*}$ & $351(73.1)$ & & 1.00 & 1.00 \\
\hline River & $5(55.6)$ & $4(44.4)$ & 0.07 & $3.4(0.9,12.9)$ & $2.5(0.5,13.7)$ \\
\hline River and tap & $5(55.6)$ & $4(44.4)$ & 0.25 & $0.58,8.23)$ & $4(0.7,26.9)$ \\
\hline \multicolumn{6}{|l|}{ Latrine availability } \\
\hline Yes & $136(27.8)$ & $354(72.2)$ & & 1.00 & 1.00 \\
\hline No & $2(25)$ & $6(75)$ & 0.863 & $0.87(.17,4.35)$ & $0.6(0.09,4.4)$ \\
\hline \multicolumn{6}{|l|}{ Habit of swimming } \\
\hline Yes & $82(26.5)$ & $227(73.5)$ & 0.46 & $0.86(0.57,1.28)$ & $1.2(0.6,2.5)$ \\
\hline No & $56(29.6)$ & $133(70.4)$ & & 1.00 & 1.00 \\
\hline \multicolumn{6}{|c|}{ Frequency of swimming per week } \\
\hline $1-2$ days & $46(22.5)$ & $158(77.5)$ & & 1.00 & 1.00 \\
\hline 3 days and above & $36(34.3)$ & $69(65.7)$ & 0.028 & $1.79(1.07,3.01)$ & $0.7(0.4,1.5)$ \\
\hline \multicolumn{6}{|l|}{ Shoe wearing habit } \\
\hline Yes & $134(27.5)$ & $354(72.5)$ & & 1.00 & \\
\hline No & $4(40)$ & $6(60)$ & 0.39 & $1.76(0.49,6.3)$ & \\
\hline \multicolumn{6}{|c|}{ Frequency of shoe wearing } \\
\hline Some times & $12(22.2)$ & $42(77.8)$ & 0.36 & $0.73(0.37,1.43)$ & $0.5(0.2,1.3)$ \\
\hline Always & $122(28.2)$ & $311(71.8)$ & & 1.00 & 1.00 \\
\hline \multicolumn{6}{|l|}{ Bathing } \\
\hline Home & $87(27.4)$ & $230(72.6)$ & & 1.00 & \\
\hline River & $36(29.3)$ & $87(70.7)$ & 0.7 & $1.09(0.7,1.73)$ & $0.8(0.35,1.8)$ \\
\hline River and home & $15(25.9)$ & $43(74.1)$ & 0.8 & $0.92(0.49,1.74)$ & $0.4(0.2,1.1)$ \\
\hline \multicolumn{6}{|c|}{ Hand washing before feeding } \\
\hline Yes & $68(18.6)$ & 297(81.4) & & 1.00 & 1.00 \\
\hline No & $70(52.6)$ & $63(47.4)$ & $<0.001$ & $4.85(3.16,7.46)$ & $5.7(3.4,9.7)$ \\
\hline \multicolumn{6}{|c|}{ Hand washing after defecation } \\
\hline No & $13(35.1)$ & $24(64.9)$ & 0.39 & $1.37(.67,2.80)$ & $1.1(0.4,2.9)$ \\
\hline Water only & $37(24.5)$ & $114(75.5)$ & 0.38 & $0.82(0.52,1.28)$ & $1.6(0.6,4.4)$ \\
\hline Water and soap & $88(28.4)$ & $222(71.6)$ & & 1.00 & 1.00 \\
\hline \multicolumn{6}{|l|}{ Washing cloth } \\
\hline Home & $84(27.4)$ & $223(72.6)$ & & 1.00 & 1.00 \\
\hline River & $44(29.5)$ & $105(70.5)$ & 0.63 & $1.12(0.72,1.7)$ & $1.2(0.6,2.6)$ \\
\hline River and home & $10(23.8)$ & $32(76.2)$ & 0.63 & $0.83(0.4,1.76)$ & $1.6(0.6,4.5)$ \\
\hline \multicolumn{6}{|c|}{ Presence of dirty materials in their } \\
\hline fingers & $93(33.1)$ & $188(66.9)$ & .002 & $1.89(1.25,2.85)$ & $2.6(1.5,4.4)$ \\
\hline $\begin{array}{l}\text { Yes } \\
\text { No }\end{array}$ & $45(20.7)$ & $172(79.3)$ & & 1.00 & 1.00 \\
\hline \multicolumn{6}{|l|}{ Practice of nail trim } \\
\hline Yes & $96(29.5)$ & $229(70.5)$ & & 1.00 & 1.00 \\
\hline No & $42(24.3)$ & $131(75.7)$ & 0.21 & $0.77(0.5,1.16)$ & $0.9(0.4,2.3)$ \\
\hline \multicolumn{6}{|l|}{ Habit of thumb sucking } \\
\hline Yes & $43(24.9)$ & $130(75.1)$ & 0.3 & $0.8(0.53,1.22)$ & $0.8(0.3,2.1)$ \\
\hline No & $95(29.2)$ & $230(70.8)$ & & 1.00 & 1.00 \\
\hline \multicolumn{6}{|c|}{ Habit of eating unwashable vegetables } \\
\hline Yes & $44(27)$ & $119(73)$ & 0.83 & $0.95(0.63,1.44)$ & $1.3(0.7,2.3)$ \\
\hline No & $94(28.1)$ & 241(71.9) & & 1.00 & 1.00 \\
\hline
\end{tabular}

\section{Discussion}

Epidemiological study on the prevalence of intestinal parasite infections in different regions/localities is a primary objective to identify communities/individuals at high risk and formulate appropriate intervention. In agreement with this view, the present study attempted to assess the prevalence of different intestinal parasitic infections and local determinant factors among Arbaminch town school children. The results of the study showed the occurrence of several intestinal parasites of public health importance among schoolchildren in three primary schools found in Arbaminch town.
Nearly every third (27.7\%) of the students in Arbaminch town were infected by intestinal parasites which was almost similar or comparable to the prevalence documented in Eastern Ethiopia, Babile town (10), Southern and central zone of Tigray (12), and Northwest Ethiopia (16) which revealed over all prevalence of $27.2 \%$, $28.6 \%$, and $34.2 \%$ respectively. Still, this result was higher than results from North west Ethiopia (22.7\%) (17) Nepal (13\%) (18), and Baglung districts of Western Nepal (19).

However, it was much lower than previously reported among different regions in Ethiopia; Southern Ethiopia around lake Awassa, North west Ethiopia, Azezo (20), North Gondar of Delgi school (13), South east of Lake 
Langano area (21) that showed prevalence of $92.7 \%$, $72.9 \%, 79.8 \%$, and $83.3 \%$ respectively. Higher prevalence of intestinal parasitic infections than the present study were also reported from other countries Saint Lucia (61.6\%) (22), Nepal (40\%) and Nigeria (67.4\%) (9).The category of the study population, the methods employed for stool examination, and the time of study may have contributed to the differences.

In this study, E.histolytica is the predominant infection in line with a study documented elsewhere (19) on the other hand, which is higher than studies carried out by Gelaw et al. (16).

Considering the prevalence rate of A. lumbricoides $(10.6 \%)$, it was lower than the value for Zarima town (23) and Azezo town (20). But, other studies done in different parts of the country showed lower rates for A.lumbricoides $(10,16,17)$.

Among the 138 positive individuals, the majority, one fifth , $108(21.7 \%)$ of the children had single infection in agreement with findings reported in other study, 108 individuals had single infection (9). The double infection rate was $5 \%$ in line with that of study done in Eastern Ethiopia, Babile (10). But quite lower than studies conducted by Gelaw et al. (16). The prevalence of multiple infections was higher compared to the previous studies (16). Sample size determination, study population and the methods used could attribute to this observed difference in detections of various parasites. On the other hand, multiple infections in this study was lower than that of the school children done other studies $(13,21)$. This difference might be due to climatic, geographic as well as study time differences in the study areas.

Differences due to gender were not observed in this current study although female (51.4\%) had slightly higher overall prevalence rate compared to male (48.6\%) which is in line with a study reported in Malaysia (24), and Nepal (18).

The finding that intestinal parasites infections are more prevalent in the age groups 10-14 years than the younger counterparts in the study area is an indication that younger children are more exposed since they usually play in the open fields (12) and they frequently involve themselves fully in activities that bring them in contact with the source of infection and this might be due to higher in number with this age category in this study. This is consistent with the findings reported from Eastern Ethiopia (10), Northwest Ethiopia (16). But the difference was not statistically significant. Findings from Saint Lucia also showed the highest infection rate among the age groups 5-14 (22) and in Western Nepal higher in the age group of 10-14 years (19).

According to this study, One of the factors strongly associated with intestinal parasites infections was low educational level of children mothers'. Children of illiterate women were more likely to get infection for at least one intestinal parasite than those who had higher educational level $[\mathrm{A} \mathrm{OR}=3.5 ; 95 \% \mathrm{CI}(1.01,11.4)]$. This finding is in line with results of other similar studies $(13,25)$. Similarly, children who did not wash their hands before eating [AOR 5.7; 95\% CI (3.4,9.7)] were more likely to acquire intestinal parasites infection than children who wash their hands before meal regularly. This finding is similar with a study done by Tadesse G. in Eastern Ethiopia (10), North west Ethiopia (20), North Gondar (26), North west Ethiopia (27) and Nepal (18). The other factor that identified in this study was children who had dirty materials in their fingers $[\mathrm{AOR}=2.6 ; 95 \% \mathrm{CI}(1.5,4.4)]$ were more likely to acquire intestinal parasites infection. This finding also supported by other studies (10), (28). Similar findings also found that poor hand washing and hygiene of nails are conducive environment for feco - oral transmission of intestinal parasites. This might be due to low knowledge of children about the feco-oral transmission of intestinal parasites through their unwashed hands.

The study has some limitations:- Firstly, only single stool sample was collected from each participant. Secondly, due to lack of antigen tests, Entamoeba histolytica and Entamoeba dispar were not separated. Lastly, as the collection period was short, no attempt was made to investigate seasonality as potential seasonal fluctuations might have affected the actual prevalence.

\section{Conclusion}

In conclusion, the result of this study indicated that intestinal parasitic infections were a common health problem with varying magnitude among the school children. This study has also shown that children mothers' educational level, nail hygienic status, and hand washing practice before meal of the children were closely associated with the prevalence of intestinal parasitic infections. Thus, there is a need for intensive and habitual health education for behavioural changes related to personal hygiene and mass treatment for the effective control of intestinal parasitic infections in the concerned area.

\section{Acknowledgements}

We would like to express our gratitude thanks to Ethiopian Institute of Water Resources, Addis Ababa University for the financial and technical support. We were also highly acknowledged for school authorities and their staffs, Arba Minch University College of Medicine and Health Sciences, Arbaminch town education and health offices, data collectors, and laboratory technologists for their un reserved support during different stages of the study. Lastly, but not the least we would like to thank all the study participants who participated in the study.

\section{Authors' Contributions}

DH: initiation of the study, design, implementation, analysis and writing. ND: design, implementation, analysis and writing. EA: design, implementation, analysis and 
writing. All authors read and approved the final manuscript.

\section{Competing Interests}

The authors declare that they have no competing interests.

\section{References}

[1] WHO. Control of Tropical Diseases. Geneva.: 1987.

[2] WHO. Control of tropical diseases. Geneva: 1998.

[3] WHO. Prevention and control of schistosomiasis and soiltaransmitted helminthiasis. Geneva: 2002.

[4] Rice J, Skull S, Pearce C, Mulholland N, Davie G, Carapetis J. Screening for intestinal parasites in recently arrived children from East Africa. Journal of paediatrics and child health. 2003;39(6):456-9.

[5] Mineno T, Avery M. Giardiasis: recent progress in chemotherapy and drug development. Curr Pharm Design. 2003; 9(11):841-55.

[6] Clark ER, Diamond L. WHO News and activities. Bulletin of the World Health Organization. 1997;75(3):291-2.

[7] AP DD, Chalmers R. Cryptosporidiosis. BMJ. 2009;339.

[8] Nematian J, Nematian E, Gholamrezanezhad A, Asgari AA. Prevalence of intestinal parasitic infections and their relation with socio-economic factors and hygienic habits in Tehran primary school students. Acta tropica. 2004;92(3):179-86.

[9] N.Opara K, Udoidung NI, Opara DC, Okon OE, Edosomwa EU, Udoh AJ. The Impact of Intestinal Parasitic Infections on the Nutritional Status of Rural and Urban School-Aged Children in Nigeria. International Journal of $\mathrm{MCH}$ and AIDS 2012; 1(1,):73-82

[10] Tadesse G. The prevalence of intestinal helminthic infections and associated risk factors among school children in Babile town, eastern Ethiopia. EthiopJHealth Dev. $2005 ; 19(2)$.

[11] Amare M, Solomon G-S, Tesfaye K. Prevalence of intestinal parasitic infections among urban dwellers in southwest Ethiopia. ethiop J Health Dev. 2007;21(1):12-7.

[12] Tadesse D, Tsehaye A. Impact of irrigation on the prevalence of intestinal parasite infections with emphasis on schistosomisis in Hintalo -Wejerat, north Ethiopia. . Ethiop J Health Dev. 2008;18(2).

[13] Ayalew A, Debebe T, Worku A. Prevalence and risk factors of intestinal parasites among Delgi school children, North Gondar, Ethiopia Journal of Parasitology and Vector Biology 2011 3(5).

[14] Abera K, Ahmed A. An overview of environmental health status in Ethiopia with particular emphasis to its organization, drinking water and sanitation: A literature survey. EthiopJHealth Dev 2005 19(2).

[15] Fentie T, Erqou S, Gedefaw M, Desta A. Epidemiology of human fascioliasis and intestinal parasitosis among schoolchildren in Lake Tana Basin, northwest Ethiopia. Trans R Soc Trop Med Hyg. 2013 Aug;107(8):480-6. PubMed PMID: 23843557. Epub 2013/07/12. eng.

[16] Gelaw A, Anagaw B, Nigussie B, Silesh B, Yirga A, Alem $\mathrm{M}$, et al. Prevalence of intestinal parasitic infections and risk factors among schoolchildren at the University of Gondar Community School, Northwest Ethiopia: a cross-sectional study. BMC Public Health. 2013;13(304):1471-2458.

[17] Amare B, Ali J, Moges B, Yismaw G, Belyhun Y, Gebretsadik S, et al. Nutritional status, intestinal parasite infection and allergy among school children in northwest Ethiopia. BMC Pediatr. 2013;13(7):1471-2431.

[18] Sah R, Paudel I, Baral R, Poudel P, Jha N, Pokharel P. Prevalence of intestinal helminthic infections and associated risk factors. Indian Journal of Community Health. 2013 $25(2)$.

[19] Shrestha A, Narayan KC, Sharma R. Prevalence of intestinal parasitosis among school children in Baglung districts of Western Nepal. Kathmandu Univ Med J. 2012;10(37):3-6.

[20] Endris M, Lemma W, Belyhu Y, Moges B, Gelaw A, Anagaw $B$, et al. Prevalence of intestinal parasite and associated risk factors of among students of Atse Fasil general elementary school Azezo, north west Ethiopia. Ethiop $J$ Health Biomed Sci, . 2010; Vol.3, (No.1).

[21] Mengistu L, Berhanu E. Prevalence of intestinal parasites among schoolchildren in a rural area close to the southeast of Lake Langano, Ethiopia. EthiopJHealth Dev 2004;8(2).

[22] Kurup R, Hunjan GS. Epidemiology and control of Schistosomiasis and other intestinal parasitic infections among school children in three rural villages of south Saint Lucia. J Vector Borne Dis. 2010;47(4):228-34.

[23] Alemu A, Atnafu A, Addis Z, Shiferaw Y, Teklu T, Mathewos B, et al. Soil transmitted helminths and schistosoma mansoni infections among school children in Zarima town, northwest Ethiopia. BMC Infect Dis. 2011;11:189. PubMed PMID: 21740589. Pubmed Central PMCID: PMC3142518. Epub 2011/07/12. eng.

[24] Ngui R, Ishak S, Chuen CS, Mahmud R, Lim YAL. Prevalence and Risk Factors of Intestinal Parasitism in Rural and Remote West Malaysia. PLoS Negl Trop Dis. 2011;5(3).

[25] Okyay P, Ertug S, Gultekin B, Onen O, Beser E. Intestinal parasites prevalence and related factors in school children, a western city sample-Turkey. BMC public health. 2004;4(1):64.

[26] Ayalew A, Debebe T, Worku A. Prevalence and risk factors of intestinal parasites among Delgi school children, North Gondar, Ethiopia. J Parasitol Vector Biol. 2011;3(5):75-81.

[27] Gelaw A, Anagaw B, Nigussie B, Silesh B, Yirga A, Alem $\mathrm{M}$, et al. Prevalence of intestinal parasitic infections and risk factors among schoolchildren at the University of Gondar Community School, Northwest Ethiopia: a cross-sectional study. BMC Public Health. 2013;13(1):304.

[28] Sah R, Paudel I, Baral R, Poudel P, Jha N, Pokharel P. Prevalence of Intestinal Helminthic Infections and associated Risk Factors. Indian Journal of Community Health. 2013;25(2):134-9. 